\title{
choer
}

\section{Arte, educação científica e política: diálogos plurais}

\author{
Thelma Lopes \\ Doutora em Ciências pelo Instituto Oswaldo Cruz - IOC \\ Espaços da Ciência da Fundação Centro de Ciências e Educação \\ Superior a Distância do Estado do Rio de Janeiro - Fundação Cecierj \\ tgardair@cecierj.edu.br
}

\section{Monica Santos Dahmouche}

Doutora em Física pela Universidade de São Paulo - USP Vice-Presidente Científica da Fundação Centro de Ciências e Educação Superior a Distância do Estado do Rio de Janeiro Fundação Cecierj

monicacecierj@gmail.com

\section{Resumo}

\begin{abstract}
Este artigo lança luz sobre a relação entre arte, educação e política, enfocando ações de educação não formal na área de divulgação científica, onde o interesse pelo diálogo entre arte e ciência é crescente. $O$ entrelaçamento de diferentes campos do conhecimento propõe desafios específicos, dispostos em múltiplas camadas. Sejam aqueles relacionados ao status atribuído a cada campo e a consequente influência nas políticas implantadas para eles ou às estratégias pedagógicas, que devem ser concebidas de modo a considerar alfabetos próprios a cada área envolvida; ou, ainda, ao fato de vivermos em uma época na qual o paradigma dominante é o científico. $\mathrm{O}$ pano de fundo da discussão aqui proposta consiste em atividades desenvolvidas pelos "Espaços da Ciência" vinculados à Fundação Centro de Ciências e Educação Superior a Distância do Estado do Rio de Janeiro (Cecierj). Constatou-se que combinar arte e ciência pode contribuir para o entendimento de afetos, desafetos, emoções, princípios históricos, razões sociais, interesses políticos, inclinações partidárias e tantos outros determinantes da produção do conhecimento.
\end{abstract}

Palavras-chave arte; ciência; democracia; divulgação científica; educação científica.

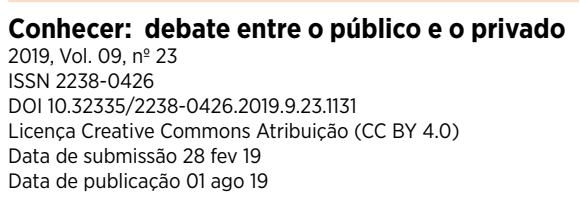




\title{
Art, science education, and politics: plural dialogues
}

\begin{abstract}
This article sheds light on the relationship between art, education, and politics, focusing on non-formal education actions in the area of scientific dissemination, where the interest for dialogue between art and science is growing. An intertwining of various fields of knowledge poses specific challenges, arranged in multiple layers. Either those related to the status assigned to each field and the consequent influence on policies deployed for them or pedagogical strategies, which should be designed in order to consider their own alphabets in each area at stake; or also to the fact that we live in an age when the dominant paradigm is the scientific one. The background for the discussion proposed here consists of activities conducted by the 'Spaces of Science' linked to the Foundation Center for Science and Distance Higher Education of the State of Rio de Janeiro (Fundação Centro de Ciências e Educação Superior a Distância do Estado do Rio de Janeiro - CECIERJ). It was found that combining art and science can contribute to understanding affections, disaffections, emotions, historical principles, social motives, political interests, partisan inclinations, and so many other determinants of knowledge production.
\end{abstract}

Key words art; science; democracy; scientific dissemination; scientific education.

\section{Arte, educación científica y política: diálogos plurales}

\section{Resumen}

Este artículo arroja luz sobre la relación entre arte, educación y política, enfocando acciones de educación no formal en el área de divulgación científica, donde el interés por el diálogo entre arte y ciencia está creciendo. El entrelazamiento de varios campos de conocimiento plantea desafíos específicos, organizados en múltiples capas. Ya sea los relacionados con el status asignado a cada campo y la consiguiente influencia en las políticas implementadas para ellos o las estrategias pedagógicas, que deben diseñarse para considerar sus propios alfabetos en cada área implicada; o también al hecho de que vivimos en una época en que el paradigma dominante es el científico. El trasfondo de la discusión que se propone aquí consiste en actividades realizadas por los "Espacios de la Ciencia” vinculados a la Fundación Centro de Ciencias y Educación Superior a Distancia del Estado de Río de Janeiro (Fundação Centro de Ciências e Educação Superior a Distância do Estado do Rio de Janeiro - CECIERJ). Se constató que combinar arte y ciencia puede contribuir al entendimiento de afectos, desafectos, emociones, principios históricos, razones sociales, intereses políticos, inclinaciones partidistas y muchos otros determinantes de la producción de conocimiento.

Palabras clave arte; ciencia; democracia; divulgación científica; educación científica.

\section{Art, enseignement scientifique et politique: dialogues pluriels}

\section{Résumé}

Cet article met en lumière la relation entre art, éducation et politique, en mettant l'accent sur actions d'éducation non formelle dans le domaine de la diffusion scientifique, où l'intérêt pour un dialogue entre art et science grandit. L'entrelacement de différents domaines de la connaissance pose des défis spécifiques, organisés en plusieurs couches. Soit ceux liés au status attribué à chaque domaine et à l'influence qui en résulte sur les politiques mises en œuvre pour eux ou sur les stratégies pédagogiques, qui devraient être conçus de manière à prendre en compte leurs propres alphabets dans chaque domaine concerné; ou au fait que nous vivons à une époque où le paradigme dominant est le scientifique. La base de la discussion proposée ici est constitué d'activités menées par les «Espaces Scientifiques » liées à la Fondation Centre pour la Science et l'Enseignement Supérieur à Distance de l'État de Rio de Janeiro (Fundação Centro de Ciências e Educação Superior a Distância do Estado do Rio de Janeiro - CECIERJ). II a été constaté que la combinaison des arts et des sciences peut contribuer à la compréhension des affections, des désaffections, des émotions, des principes historiques, des raisons sociales, des intérêts politiques, des inclinations partisanes et de tant d'autres déterminants de la production de connaissances.

Mots-clés art; science; démocratie; diffusion scientifique; enseignement scientifique. 


\section{Introdução}

No Brasil, a educação em artes está prevista nos Parâmetros Curriculares Nacionais de Arte ( $P C N$ ) e deve ocorrer desde o Ensino Fundamental, enfocando não necessariamente o aprendizado de habilidades técnicas, mas contribuindo para a formação integral do cidadão e para a compreensão de formas artísticas de diferentes naturezas e povos. Propósitos como estimular leituras criativas do mundo, bem como a sensibilidade perceptiva e a conscientização da dimensão social das artes vão ao encontro das metas discriminadas no PCN. Destaca-se na propositiva a formulação de 3 eixos: a) produção, na qual está envolvida a sugestão de técnicas, temas e disponibilização de materiais; b) fruição, em que se vincula contextualização de obras, compreensão de seus níveis de dificuldade e apreciação; e c) reflexão, que pode ser compreendida como construção de conhecimento gerado a partir do trabalho artístico.

Contudo, na prática, dada a realidade brasileira e o status da arte como campo do conhecimento, não constitui tarefa fácil concretizar os preceitos dos PCNs, seja no âmbito da educação formal, seja nas iniciativas desenvolvidas no domínio da educação não formal. Somente com a Lei n. 5.692 (Lei de Diretrizes e Bases [LDB], 1971) a arte foi incluída no currículo escolar como "atividade educativa". Na década de 1990, música passou a ser disciplina obrigatória e somente em 2016, teatro, artes visuais e dança se integraram ao currículo do ensino básico como mandatórias. Esse foi um avanço importante. A obrigatoriedade contribui para consolidar, pouco a pouco, o entendimento de que os conteúdos de artes são imprescindíveis e basilares para a formação global do indivíduo.

Já no campo da educação não formal há, cada vez mais, associação entre artes e ciências, principalmente em ações de divulgação científica, que podem ser facilmente encontradas em centros e museus de ciências ou em praças públicas, por ocasião de eventos temáticos, como a Semana Nacional de Ciência e Tecnologia (SNCT) e até nas escolas. Por princípio, em sua essência, tais ações apresentam como principal objetivo tornar temas e conteúdos relativos a diversas ciências palatáveis ao público não especializado. Para tanto, faz-se necessário o diálogo com diferentes linguagens para que o discurso científico possa ser apresentado de modo compreensível e atraente aos que não estão plenamente familiarizados com a área das ciências. Nessa direção, múltiplas formas de arte têm sido exploradas, como peças de teatro, vídeos e filmes cujas temáticas abordam assuntos referentes ao mundo das ciências ou a biografia de cientistas, assim como exposições que fazem uso das artes plásticas, como a pintura ou o desenho.

No cenário em que se intercambiam diversas áreas do saber e de atuação humana, com características distintas, mesmo considerando os muitos pontos de contato e as afinidades entre elas, multiplicam-se enfrentamentos, colocando em plano de análise questões de diversas categorias. Cada campo do conhecimento instila sua própria mitologia, utiliza 
signos típicos, explora maneiras de operar específicas e propõe perguntas intrínsecas aos seus respectivos objetos de estudo. Assim, criam-se tensionamentos, e, por vezes, equívocos e estereótipos que precisam ser discutidos e eliminados, visando a constituir as bases para processos educativos plurais.

\section{A sala de aula, outros lugares onde se aprende, a arte e a ciência}

Aprender é um processo ininterrupto que ocorre durante toda a vida. Seja nos bancos escolares ou nos bancos dos bares, dos trens ou dos lares, aprendemos algo a cada dia. A escola é um dos locais onde se pode aprender. Os processos de aprendizagem se dão em diferentes níveis, espaços e modalidades, e tais diferenças não devem ser ordenadas em uma suposta escala hierárquica. Existem diversas formas de aprender e ensinar que podem ser complementares, o que não significa que, por vezes, não haja incompatibilidade e conflito entre elas. Surgem algumas denominações na tentativa de categorização. A chamada "educação formal" é caracterizada por se apresentar de modo bastante estruturado, no qual se segue um programa preestabelecido e onde se conta com certificação. Moacir Gadotti (2005, p. 2) delimita com clareza:

\footnotetext{
A educação formal tem objetivos claros e específicos e é representada principalmente pelas escolas e universidades. Ela depende de uma diretriz educacional centralizada como o currículo, com estruturas hierárquicas e burocráticas, determinadas em nível nacional, com órgãos fiscalizadores dos ministérios da educação. A educação não formal é mais difusa, menos hierárquica e menos burocrática. Os programas de educação não formal não precisam necessariamente seguir um sistema sequencial e hierárquico de "progressão". Podem ter duração variável, e podem, ou não, conceder certificados de aprendizagem.
}

No entanto, na busca por definir "educação não formal" e "informal", as delimitações não parecem tão evidentes. Maria G. Gohn (2006, p. 28) explica que, muitas vezes, o termo não formal é usado por alguns pesquisadores como sinônimo de informal: 
processo de socialização - na família, bairro, clube, amigos etc., carregada de valores e culturas próprias, pertencimento e sentimentos herdados: e a educação não formal é aquela que se aprende "no mundo da vida", via os processos de compartilhamento de experiências, principalmente em espaços e ações coletivas cotidianas.

$\mathrm{Na}$ tentativa de melhor demarcar as diferenças entre as modalidades de educação, a autora prossegue perguntando sobre quem seria o educador em cada campo de educação que analisamos; onde educamos e qual seria o espaço territorial no qual transcorrem os atos educativos. As questões contribuem para apontar pistas que explicitam diferenças, mas, ainda assim, em relação à educação não formal e informal, resta, também, certo grau de dubiedade. Este estudo não visa ao aprofundamento dos termos que designam diferentes modalidades de educação. Buscamos discutir a interação entre linguagem artística e divulgação científica, que, segundo Gohn (2006), pode ser caracterizada como educação não formal.

Ainda no campo da educação, Freire (1983) postula que, em sentido estrito, ninguém educa ninguém, reafirmando a convicção de que é imprescindível criar condições que favoreçam o aprendizado e que tais condições serão tão mais favoráveis quanto mais apto o sujeito a olhar para si e construir, a partir dele próprio, as condições mais adequadas ao seu modo e ritmo de aprender. Não se trata de desconsiderar as estruturas externas e os agentes concretos necessários para viabilizar a educação como projeto público e social, mas sublinhamos, aqui, a visão de Freire (1983) no que se refere à necessidade de dirigirmos o olhar para dentro de nós, como condição para entender como os processos educativos são desencadeados. Freire (1983, p. 27) afirmou: "comecemos por pensar sobre nós mesmos e tratemos de encontrar, na natureza do homem, algo que possa constituir o núcleo fundamental onde se sustente o processo de educação".

Para Freire (1983), educar implica percurso no qual o homem deve ser sujeito de sua própria trajetória, e não objeto dela. Daí a ideia de que ninguém educa ninguém. Se tomamos por base as palavras do autor pernambucano, a discussão sobre aprendizagem não pode dispensar a reflexão sobre os fatores emocionais aí envolvidos. Os questionamentos que se seguem são:

- Uma vez que a emoção deve estar incluída no processo de aprendizagem, ao pensar em disciplinas como ciências, por exemplo, como conjugar afetos e conteúdos?

- Como estimular a alegria de aprender em meio a tanta sisudez, característica dos já estigmatizados discursos científicos, a despeito de algumas recentes iniciativas de translação por meios mais amigáveis?

- Quais seriam os caminhos possíveis? 


\section{Arte e educação científica}

A linguagem artística é, potencialmente, dotada da capacidade de despertar a fruição, suscitar emoções e entreter, que, por sua vez, constituem qualidades de extrema importância para os processos educativos. O psicólogo estadunidense Carl Rogers se dedicou à psicopedagogia e sua obra enfatiza a importância de uma abordagem globalizante que inclua sentimentos e intelecto para a promoção de aprendizagem mais duradoura e abrangente. Sobre esse aspecto, em consonância com Rogers, Marco A. Moreira (1999, p. 144), que se dedicou à investigação de teorias da aprendizagem e metodologias de ensino, explica:

[...] a aprendizagem eficaz é a da pessoa que se deixa envolver, totalmente, por si mesma. Não é uma aprendizagem somente cognitiva, do "pescoço para cima”. É uma aprendizagem que envolve tanto o aspecto cognitivo como afetivo da pessoa, é "visceral”, profunda e abrangente.

Assim, as artes aliadas aos processos de educação em ciências podem contribuir sobremaneira para desconstruir estereótipos, estigmas e visões reducionistas acerca da prática científica. Contudo, na equivocada supremacia do "cientificamente comprovado", devemos atentar para não encarar as artes como mera ferramenta destinada a veicular conteúdos das ciências, sob o risco de apequenar as duas. A interação entre arte e ciência será tão mais benéfica na medida em que primar pelo diálogo de excelência entre os múltiplos saberes e pela compreensão de que ambas constituem pontos de vista e formas de expressão. Sob essa perspectiva, Lopes (2018a) analisa:

\footnotetext{
Tal qual a Ciência, a Arte é forma de ver, antever e inscrever. É meio indispensável para enxergar soluções em um ambiente cada vez mais complexo, hostil e conflitante. Alimentar a falsa incomunicabilidade entre elas, mais que um equívoco, é contribuir para uma sociedade desigual, na qual não se reconhece na pluralidade do conhecimento, poderoso aliado para leitura plena de um mundo tão diverso, rico de significados e cambiante.
}

A questão capital que emerge diante da proposição de conjugar saberes em prol de um objetivo pedagógico é:

- Como traduzir em ações práticas a interação de diferentes áreas do conhecimento, de modo a conservar as especificidades e não subjugar uma a outra? 
Trata-se de um desafio a ser compreendido e encarado, que se desdobra em tantos outros, o qual tem sido enfrentado no planejamento das atividades dos Espaços da Ciência (ECs) vinculados ao setor de divulgação científica da Fundação Centro de Ciências e Educação Superior a Distância do Estado do Rio de Janeiro (Cecierj), que detalhamos adiante. Antes, contudo, é preciso contextualizar o cenário em que tais ações se inserem, já que os ECs estão estabelecidos em um universo maior de iniciativas que visam à popularização de conhecimentos.

\section{Arte e ciência em museus e centros de ciência}

O diálogo entre arte e ciência vem sendo cada vez mais explorado tanto no âmbito da divulgação científica quanto no campo da educação em ciências. As iniciativas incluem diferentes linguagens artísticas. Os centros e museus de ciência constituem loci onde a educação não formal é dominante, e, não raro, configuram pontos de convergência de artistas amadores, cientistas, museólogos e curadores de exposições científicas que desempenham o papel mediador do processo de criação artística, como apontado por Agostinho e Casaleiro (2015), ao se referir ao Museu "CosmoCaixa", de Barcelona, cujo curador, Jorge Wagensberg (2006), físico-museólogo catalão, desenvolveu o conceito de museologia total.

Em sua conceituação, Wagensberg (2006) organizou exposições de ciências que buscavam integrar elementos baseados em conjunto de pressupostos no qual arte e ciência ocupariam dois polos diferentes em relação ao modo como operam, mas que dialogariam harmonicamente na exposição museológica. No cenário brasileiro, dentre as ações que visam ao diálogo entre arte e ciência, destaca-se o teatro, com mais de uma dezena de instituições científicas (L. M. Moreira \& Marandino, 2015) dedicadas ao desenvolvimento de atividades, dentre produção de esquetes, mediações teatralizadas e até temporadas regulares de espetáculos (Gardair \& Schall, 2009). "Catavento Cultural e Educacional", "Museu Histórico Nacional”, "Museu da Vida", "Seara da Ciência" e "Museu Ciência e Vida" são algumas das entidades promotoras de ações multidisciplinares envolvendo a linguagem teatral.

Também há ações que associam música e temas científicos, em que se explora, por exemplo, aspectos da entomologia a partir de repertório de canções da música popular brasileira (MPB). Nesse caso, as composições constituem ponto de partida para discutir conceitos, relações e estereótipos acerca do papel dos insetos na natureza e a visão da população leiga sobre os pequenos animais (Serpa, 2016). Destaca-se, ainda, o projeto "Cyclophonica" - orquestra volante sobre bicicletas, liderada por Leonardo Fuks, na qual a música é relacionada a conceitos de óptica. 
Fiç̧ão científica, quadrinhos, literatura e cinema também vêm aproximando-se das ciências. Desde as primeiras iniciativas brasileiras de histórias em quadrinhos, explorando o universo científico, como aquelas desenvolvidas por Leopoldo De Meis e Diucênio Rangel (1998), até as "Cientirinhas" de Luiciano Queiroz e Marcos Merlin, produzidas desde 2016 (Caires, 2019), investe-se na combinação entre linguagem visual, textual e conteúdo científico, objetivando popularizar conteúdos e entreter. No mundo da literatura, a icônica história da Mary Shelley, "Frankeinsten ou Prometeu moderno", é considerada a primeira obra de ficção científica. Na trama, Lopes (2018b) observa, "a responsabilidade na aplicação dos conhecimentos, a arrogância e orgulho intelectuais ou mesmo a desmesura do saber, estão entre os questionamentos suscitados pelo livro que vem sendo lido por gerações há dois séculos". A ficção científica também se estende ao cinema, arte com a qual a ciência e a tecnologia guardam especial relação:

\footnotetext{
Se pensamos na relação entre tecnologia e cinema, é possível afirmar que esta é uma arte que só foi possível pelo desenvolvimento de equipamentos tecnológicos que envolvem desde recursos fotográficos até sofisticados equipamentos de projeção atuais. A tecnologia na indústria cinematográfica influencia diretamente a linguagem da grande tela. A sonorização de imagens é um exemplo dessa influência, assim como o advento das cores, os efeitos visuais proporcionados pela computação gráfica ou a produção de telas que geram a ilusão de 360 graus (Lopes, 2005, p. 403).
}

A história do cinema pode ser contada a partir da busca do homem para reproduzir a imagem em deslocamento. Há 12 mil anos, pinturas rupestres representavam animais com 8 patas, na tentativa de ilustrar o movimento. A partir do interesse primitivo, o homem moderno buscou criar mecanismos de apresentação sequenciada de imagens para produzir a sensação de movimento de gravuras estáticas. Em 1833, o britânico W. G. Horner concebeu o zootrópio, aparelho baseado na sucessão circular de imagens que, ao ser giradas, davam a ilusão óptica de movimento contínuo. Entre 1876 e 1877, Charles-Émile Reynaud, professor de ciências e pintor francês, apresentou o praxinoscópio, invenção que realizava o mesmo processo de percepção da animação obtida pelo zootrópio, mas substituindo os orifícios por pequenas tiras de espelho.

Pouco a pouco, os equipamentos foram aprimorados até que Reynaud concebesse o teatro óptico, dispositivo que conjugava espelhos e lentes, permitindo a projeção de animações complexas, em frequência de 15 quadros por segundo, e com duração média de 15 minutos. As pantomimes lumineuses, como eram chamadas as apresentações, alcançaram êxito junto ao público, com sala de exibição lotada. O Teatro Óptico atingiu público superior a 500 mil espectadores. Contudo, tratava-se de processo artesanal e 
exaustivo, sendo necessário colorizar milhares de imagens sequenciais, uma a uma, de modo a considerar a sincronia com a trilha sonora das histórias, orquestrada ao vivo.

Foi com o cinematógrafo, patenteado pelos Irmãos Lumière, em fins do século XIX, que se tornou possível filmar e projetar cenas em maior escala. No início, a tecnologia cinematográfica se limitava ao registro de cenas cotidianas e as relações do público com a novidade que gravava a realidade eram, naturalmente, bem diferentes das atuais em 1895. As diminutas taxas de alfabetização, a baixa escolaridade e a precária compreensão das leis da física óptica conferiam uma atmosfera de magia e crendices ao cinema. A plateia ficava atônita diante das imagens projetadas.

Perante a exibição de Arrivée d'un train en gare à La Ciotat, a audiência acompanhou a chegada de um trem à estação e o desembarque de passageiros. Na ocasião, parte da plateia correu em direção ao fundo da sala, temendo ser atropelada. Os que foram filmados acenavam para a câmera. Nos breves 60 segundos de duração do filme precursor, não havia consciência da revolução que estava por vir, na qual arte e tecnologia estavam imbricadas. Naquele momento, sequer se atribuía ao cinema o caráter (ou status) de arte.

Enquanto os Irmãos Lumière aprendiam a explorar o novo produto técnico-científico, Georges Méliès utilizou a "máquina de filmar" a partir de sua experiência como mágico e diretor de teatro. Assim, produziu em 1902 o primeiro filme com cenas e expressão dramática. O curta metragem de 12 minutos, Le Voyage dans la Lune, foi inspirado em um dos romances de Júlio Verne e é considerado o primeiro filme de ficção científica. Nele aparecem as primeiras representações de cientistas na grande tela. E, desde então, o mundo científico vem sendo explorado de diversas formas e em diálogo com diferentes períodos, já que, como observa Ferreira (2010, p. 265), "a obra de arte traduz os conflitos históricos e os problemas políticos, morais ou epistêmicos do seu tempo".

Nas ações pedagógicas unindo ciência e cinema, destacam-se programas como o "VerCiência", mostra internacional de cinema na TV, cujo objetivo é estimular a propagação da cultura científica por meio de diferentes tecnologias audiovisuais, e a "Mostra Científica do Cineclube CEDERJ", desenvolvida, principalmente, nas edições da SNCT. Trata-se de um programa de exibição de filmes no interior e na capital do Rio de Janeiro. O principal objetivo é estimular o gosto pela arte cinematográfica e o olhar crítico em relação às artes. O acervo é composto por títulos de variados estilos, gêneros e épocas.

Vale salientar que nem toda produção tecnológica é fruto de pesquisa científica, mas, comumente, ambas estão interligadas. No caso da linguagem cinematográfica, além de seu nascimento ter sido propiciado pelo avanço da tecnologia, ela tem sido veículo de temas científicos, assim como maneira de apresentar biografias de personagens das ciências, tendo mostrado-se excelente estímulo para o debate da produção científica de modo humanizado, contextualizado e em diálogo com seu tempo, como corrobora Oliveira (2006, p. 141): 


\begin{abstract}
Filmes expressam o olhar não só das pessoas envolvidas em sua montagem, mas, indiretamente, revelam o imaginário de seus espectadores, pois antes mesmo de vir a contribuir na formação e reforço de hábitos culturais, a produção de um determinado filme leva em conta a visão de seu público-alvo, seu universo de referências, conhecimentos e expectativas. Nesse sentido revelam, mais do que outras produções artísticas como um livro ou pintura, o olhar de uma época ou de uma sociedade.
\end{abstract}

No campo das artes plásticas, um bom exemplo de associação entre ciência e arte são as exposições do brasileiro Candido Portinari, que deixou vasto acervo de obras. Algumas delas estão retratadas na exposição "Portinari: Arte e Ciência" (O Projeto Portinari, 2016) e "Portinari: Arte e Meio Ambiente" (Casa da Ciência, 2018).

A primeira é composta por 14 módulos, que comportam 30 réplicas de obras de Portinari associadas a um conjunto de atividades de arte, ciência e educação, nas quais se incluem recursos e estratégias, como: experimentos científicos, oficinas de arte, jogos, informática, painel ilustrativo etc.

A segunda reúne réplicas digitais de 28 obras do pintor de Brodowski em que foram selecionadas imagens de paisagens, flora e fauna brasileiras, colheitas e do homem brasileiro, compondo uma exposição que, além de mostrar o trabalho do artista, almeja emocionar e envolver os visitantes, mobilizando-os e, por meio da arte, despertá-los para a importância de transformar o mundo em espaço onde a fraternidade entre os homens seja dominante.

Tal exposição foi organizada por ocasião da Conferência da Organização das Nações Unidas (ONU) sobre Desenvolvimento Sustentável, a Rio+20 (Comitê Nacional de Organização Rio+20, 2011), para integrar um conjunto de atividades de popularização da ciência realizadas durante o evento. As duas exposições itineraram por vários museus de ciência, onde se pôde explorar interfaces e desenvolver atividades relacionadas, como oficinas de origâmi e de desenho, proporcionando ao visitante exercitar e manifestar sua criatividade, contribuindo para a compreensão, de maneira lúdica e por meio da arte, de aspectos científicos. Dessa forma, pôde-se estabelecer relações entre as obras de Portinari e fenômenos científicos, tanto no que se refere às técnicas pictóricas utilizadas pelo artista quanto aos elementos representados nas obras, ainda que, não necessariamente, o pintor tenha cogitado tais relações na concepção original de seus quadros.

Destaca-se, também, a exposição realizada no Museu da Vida, nomeada "Corpo na Arte Africana" (ERA Virtual, 2010), cujos objetos colecionados por pesquisadores da Fundação Oswaldo Cruz (Fiocruz) que estiveram em missão na África foram reunidos em 5 módulos que abordavam o corpo sob diferentes perspectivas, a saber: a) "Corpo individual \& Corpos múltiplos"; b) "Sexualidade \& Maternidade"; c) "A Modificação e a Decoração 
do Corpo"; d) "O Corpo na Decoração dos Objetos"; e e) "Máscaras como Manifestação Cultural". Ressalta-se, nesse caso, a interação de recursos das artes plásticas com a antropologia e história - ciências categorizadas como humanas e sociais.

Tamanho é o interesse pela conjunção entre arte e ciência na área da educação científica que há defensores da aglutinação dos 2 campos, criando um terceiro e adotando um termo único: ArtScience. Em manifesto, 4 autores dos EUA (Root-Bernstein, Siler, Brown, \& Snelson, 2011) postulam princípios para sintetizar modos de operação da pesquisa e expressão artística e científica, fundindo faculdades subjetivas, emocionais, objetivas, racionais etc. No Brasil, o termo foi traduzido como CienciArte. Sobre esse aspecto, uma das pioneiras no estudo desta abordagem, Araújo-Jorge et al. (2018, p. 26), explica:

\footnotetext{
CienciArte incorpora a convergência de processos e habilidades artística e científica, e não a convergência de seus produtos. CienciArte não é Arte + Ciência ou Arte-e-Ciência ou Arte/Ciência, nos quais os componentes retêm suas distinções e compartimentalização disciplinares. CienciArte transcende e integra todas as disciplinas ou formas de conhecimento.
}

Contudo, na prática, o convívio entre ciência e arte oferece alguns desafios, uma vez que envolve dois amplos campos do conhecimento, que se subdividem em outros e, aparentemente, são muito distantes entre si. A palestra de Charles Percy Snow, proferida na Universidade de Cambridge, em 1959, sobre o que ele denominou "as duas culturas", constitui referência para a discussão sobre as relações entre as áreas aqui em questão. Em sua fala, criticou veementemente a cisão entre as humanidades e as ciências naturais, advertindo sobre os preconceitos mútuos, enfrentados por ele próprio, já que transitava por múltiplas áreas e defendeu a melhor comunicação entre as "duas culturas".

\section{Concretizando relações e políticas públicas: os Espaços da Ciência vinculados à Cecierj}

$\mathrm{Na}$ época atual, o dia a dia é perpassado pelas ciências e tecnologias. A todo momento, importantes decisões são tomadas com base em argumentação científica. As repercussões se estendem aos mais diferentes níveis e âmbitos, sejam eles sociais, econômicos ou culturais. Desse modo, as ciências não podem estar circunscritas ao mundo dos especialistas. Para Feyerabend (2011, p. 120), "os leigos podem e devem supervisionar a Ciência". Ademais, "em uma sociedade democrática, instituições, programas de pesquisa e sugestões têm [...] de estar sujeitos ao controle público", enfatiza o mesmo Feyerabend 
(2007, p. 8). Assim, é fundamental o desenvolvimento de estratégias voltadas ao estímulo da reflexão sobre a prática científica e, sob essa perspectiva, a associação com as artes é ímpar.

Os ECs da Cecierj são minicentros de ciência situados no interior do Estado do Rio de Janeiro, onde são desenvolvidas atividades de divulgação científica variadas, tais como exposições interativas, sessões de planetário, oficinas, feiras de ciências e atividades durante a SNCT. Os ECs são geridos em parceria com as secretarias de educação locais e o setor de divulgação científica da Cecierj, que, nessa relação, é responsável, como Gardair, Dahmouche e Fiães (2018, p. 519) explicam,

[...] pela capacitação dos mediadores que conduzem tais atividades e pela proposição de programação suplementar, como eventos multidisciplinares, exposições temáticas, oficinas voltadas para docentes e estudantes, que por vezes são, parcialmente, financiadas por agências de fomento. Em termos físicos os ECs contam com um conjunto de equipamentos científicos interativos que ficam expostos de modo a facilitar a experimentação por parte dos visitantes.

A maior parte do financiamento para o desenvolvimento e a implementação das atividades advém do orçamento das prefeituras em questão, também sendo responsável pela preservação do edifício, recursos destinados à infraestrutura e manutenção de pessoal. Agências de fomento, como a Fundação de Amparo à Pesquisa do Estado do Rio de Janeiro (FAPERJ) e o Conselho Nacional de Desenvolvimento Científico e Tecnológico (CNPq), também assumem importante papel no apoio à concepção das ações pedagógicas. A interface com o público visitante dos ECs, seja espontâneo ou agendado, é realizada pelos mediadores locais, capacitados pela Cecierj, que tem como principais funções: a) facilitar a interação do público com as exposições; b) desenvolver oficinas; e c) mediar as demais atividades oferecidas nos ECs.

Nesse cenário, no qual compreendemos as políticas públicas como o conjunto de medidas e ações suportadas institucionalmente de modo sistemático, em diferentes âmbitos e por diversas entidades, reafirmamos o compromisso com a educação pública de excelência, ao desenvolver ações voltadas ao ensino não formal, envolvendo múltiplos atores sociais, variados campos do saber e primando pela diversidade cultural no ensino de ciências associadas às artes, de modo gratuito e irrestrito. Contudo, algumas dificuldades despontam ao longo do percurso. Muitas vezes nos deparamos com políticas de governo que, diferentemente das políticas de Estado, não estão, necessariamente, amparadas pela Constituição da República Federativa do Brasil (1988) no que concerne à continuidade dos processos. Segundo Gardair et al. (2018, p. 519): 


\begin{abstract}
No que se refere aos objetivos pedagógicos a serem alcançados, pretende-se apresentar e discutir temas e conteúdos do campo das ciências de forma contextualizada, atraente e acessível ao público não especializado. Constituir local de apoio aos docentes da região visando desenvolver e aprimorar suas práticas didáticas é também meta dos ECs. Trata-se de uma ação de interiorização que busca promover a popularização da ciência e tecnologia especialmente voltada para os estudantes e professores da rede escolar regional.
\end{abstract}

As atividades dos ECs são planejadas de modo a apresentar as ciências como mais uma das produções do conhecimento que o homem é capaz de gerar. Busca-se não absolutizar o saber científico, explorando-o em diálogo com outros estudos, estimulando a reflexão acerca do impacto social da produção em ciências. Contribuir para a desconstrução de estereótipos e estigmas relacionados à prática científica também é uma das metas a considerar na formulação da programação dos ECs, salientando os componentes de subjetividade e afetividade que podem compor a metodologia científica. Sobre esse aspecto, Ferreira (2010, p. 265) analisa:

\footnotetext{
A racionalidade científica moderna não se caracteriza por seu caráter contemplativo, ela se constitui como um saber que propõe uma intervenção na natureza com a intenção de dominá-la, transformá-la, agir sobre ela. Seus conceitos e pressupostos reproduzem uma concepção de mundo mecanicista, dualista, quantitativista e ordenadora. Ou seja: é um tipo de conhecimento que, ao interferir, modela, constrói a realidade, organiza segundo seus interesses, seus pressupostos e seus métodos, ela age no social, embora isso nem sempre fique explícito. Nessa racionalidade, a subjetividade é um problema a ser evitado.
}

Assim, as atividades dos ECs foram concebidas considerando a importância de apresentar e discutir conteúdos de forma contextualizada. Nessa direção, destacamos duas ações específicas, nas quais a associação entre artes plásticas e temas científicos foi explorada na prática, visando a não incorrer em hierarquização dos conhecimentos e oferecer múltiplos pontos de vista sobre um tema único. Trata-se da exposição itinerante "O Céu dos Artistas" e da oficina "Comendo com os Olhos".

\title{
O Céu dos Artistas: uma exposição interativa em diálogo com as ciências
}

O céu desperta a curiosidade dos homens desde tempo remotos e, como Lexicon (1990, p. 53) afirma, "tem importante papel nas concepções mitológicas e religiosas de 
quase todos os povos". Uma das possíveis explicações para o fascínio que o céu exerce sobre o homem é a relação estabelecida entre céu e fertilidade na terra, bem como um rico imaginário sobre deuses e entidades que regeriam nossas vidas e povoariam esse espaço que está acima de nós.

Para Lexicon (1990, p. 53), estão associados ao mundo celeste "movimentos regulares e ordenados dos astros, as chuvas [...] fertilizantes e necessárias à vida, o temor e o respeito despertado pelos fenômenos da natureza como a trovoada, o raio, os cometas os meteoritos, o arco-íris". Os mistérios e certa inacessibilidade do céu, provavelmente, também são responsáveis pelo interesse despertado no ser humano. O firmamento, as estrelas, os astros, os planetas, as nuvens, o sol, nada disso é palpável. Só podemos contemplar o que é visível a olho nu e imaginar o que não é possível ver. O céu é fonte, ainda, de inspiração e criação inesgotáveis. Quantos de nós não vemos centenas de formas nas nuvens espalhadas em uma tarde de céu claro? Alvarez (2008, p. 390) salienta: "o céu azul é o espaço aéreo sem limite, onde o sonhador se perde nesse espelho sem fundo, sem forma e sem direção".

Artistas de diferentes épocas e estilos se dedicaram a retratar o céu. Nas artes plásticas, podemos citar Rene Magritte, Edvard Munch ou Vincent Van Gogh, por exemplo. Fato é que os temas relacionados ao céu podem constituir ótimo ponto de partida para a articulação de diferentes campos do conhecimento, considerando a inspiração poética que desperta e o imenso conjunto de dados no qual se constitui para as ciências.

O "Céu dos Artistas" é uma exposição itinerante, produzida com recursos do edital "Apoio à Produção e Divulgação das Artes/FAPERJ" e da Cecierj. Com projeto expográfico de Andréa Fiães e de curadoria de Thelma Lopes, visa a estimular a discussão sobre possíveis relações entre ciência e arte por meio da divulgação de obras de pintores consagrados articulada a outros saberes e à ambiência histórica e cultural às quais estão ligados. Incluem-se, também, como metas da atividade, a promoção de espaço de fruição das artes e o estímulo à formação de público apreciador das artes plásticas. A exposição é constituída por reproduções de obras que retratam o céu e são exibidas em conjunto com sessões de planetário, visando a dispor discurso artístico e científico acerca de um mesmo assunto.

A pesquisa para composição de "O Céu dos Artistas" ocorreu em 3 aportes principais: a) conteúdos; b) estratégias pedagógicas a desenvolver para apresentação dos referidos conteúdos; c) suportes e materiais adequados aos objetivos estéticos e educacionais, levando em conta a exequibilidade e durabilidade. Foram selecionados 7 pintores. No total, a exposição é composta por 13 painéis, que foram agrupados em 4 conjuntos: a) um painel de abertura; b) 7 painéis com reproduções de obras de arte; c) 2 painéis de mitologias e canções sobre o céu; e d) 3 painéis interativos com jogos imantados sobre o céu. 
Figura 1 Painel da exposição "Céu dos Artistas"
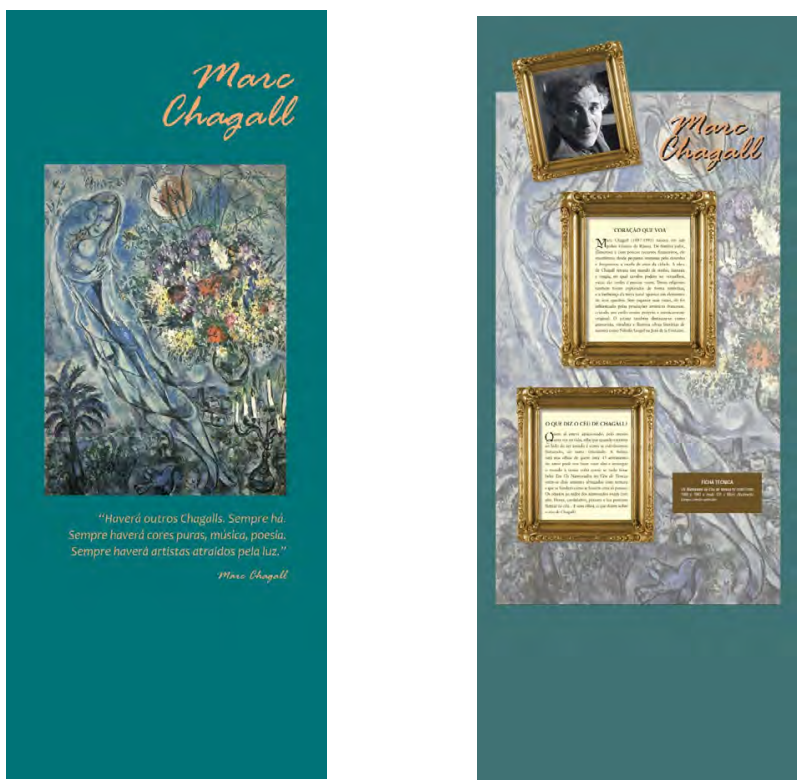

Fonte: Elaborada pelas autoras.

As obras reproduzidas foram: a) "Os Amantes no Céu de Veneza" (Marc Chagall); b) "Sol Poente" (Tarsila do Amaral); c) "A Queda de Ícaro" (Henri Matisse); d) "Céu Azul" (Wassily Kandinsky); e) "O Sol” (Edvard Munch); f) "Noite Estrelada" (Van Gogh); e g) "Constelações" (Joan Miró). A face da frente de cada um desses painéis contém a reprodução da obra e uma frase do pintor. Na parte posterior há uma foto do artista, informações biográficas, e espaço dedicado às informações técnicas do quadro, tais como: a) tamanho; b) título; e c) museu ou coleção particular onde se encontra (Figura 1).

Uma vez selecionados, pintores e obras, sublinhamos a ideia que permeia toda a exposição: a de que há diferentes maneiras de ver e expressar o mundo, sendo as artes e as ciências algumas delas. Desse modo, entendemos que, como estratégia pedagógica para ressaltar a noção de pluralidade sobre um mesmo tema, seria fundamental incluir dados ligados à antropologia e mesmo a outras artes, além da pintura. Assim, agregamos aos painéis dos 7 pintores mais 2, nomeados "O céu e seus Significados", contendo breves histórias e lendas de diferentes povos sobre o céu, e "O Céu na Boca dos Poetas", com músicas que tematizam. Optamos, ainda, pela inclusão de painéis interativos.

Acerca dos suportes materiais, os quesitos norteadores foram: a) durabilidade; b) facilidade de montagem e desmontagem; c) acondicionamento dos painéis; e d) acabamento estético. Assim, utilizamos totens modulares e expositores portáteis, aos quais foram aplicados banners de poliéster ou lona. Vários testes de impressão foram realizados para constituir imagens de ótima qualidade. As reproduções das obras selecionadas foram 
feitas a partir de figuras de livros e tratadas digitalmente, para obter um resultado estético satisfatório. Cabe salientar que, ao longo da mediação da exposição, ponderamos com os visitantes o fato daquelas imagens ali reproduzidas serem, apenas, referências visuais dos originais. Apontamos diferenças como as de tom, textura e tamanho, por exemplo.

Figura 2 Pesquisa de materiais e teste de impressão

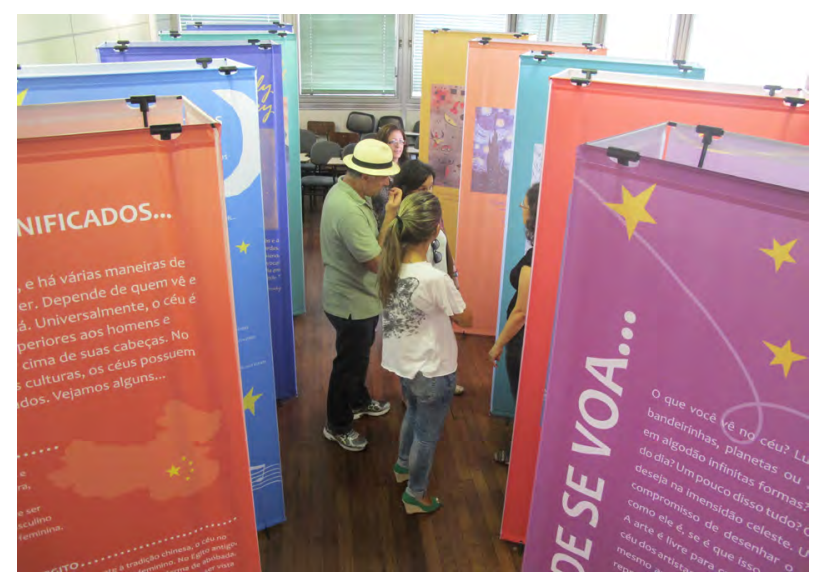

Fonte: Elaborada pelas autoras.

Foi realizado um conjunto de ações voltadas à capacitação do grupo de mediadores, composto por estudantes de diferentes graduações, para que atuassem como facilitadores dos conteúdos apresentados e das relações propostas na exposição. Tais ações incluíram a elaboração de apostila e encontros presenciais nos quais se discutiu história da arte, montagem dos painéis, dinâmicas de recepção e acolhimento do público, bem como estratégias de associação dos temas artísticos à visitação ao planetário.

Figura 3 Capacitação de monitores/facilitadores da exposição
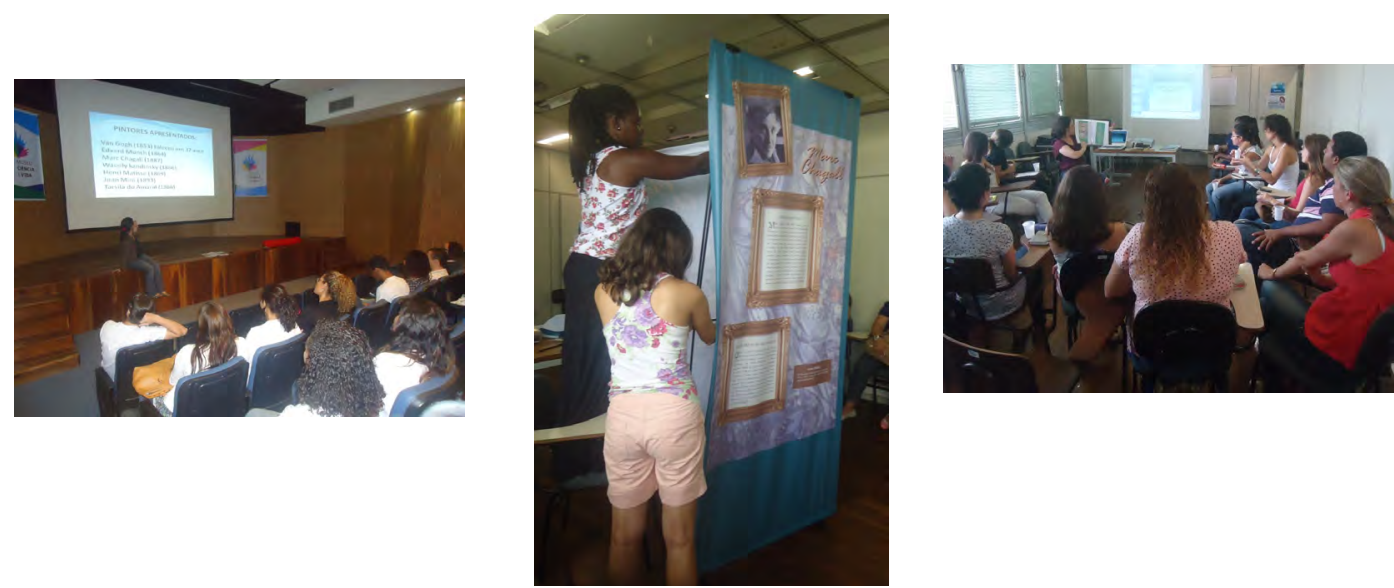

Fonte: Elaborada pelas autoras. 
Itinerante, desde sua inauguração em abril de 2013 até fevereiro de 2019, a exposição foi apresentada em localidades do Rio de janeiro, onde, destacamos, os aparelhos culturais são reduzidos, tais como: a) Duque de Caxias; b) Teresópolis; c) Sapucaia; d) Três Rios; e e) Paracambi. No total, obteve-se público estimado de 25 mil pessoas.

\section{Comendo com os Olhos: oficina integrada de arte e ciência}

A oficina "Comendo com os Olhos" foi especialmente concebida por ocasião da 13a edição da Semana Nacional de Ciência \& Tecnologia, realizada em 2016, cujo tema foi "Ciência Alimentando o Brasil". A principal meta consistiu em explorar aspectos sociais e culturais dos alimentos relacionados a conteúdos de variadas ciências, tendo como noção basilar a compreensão de que o hábito alimentar é um dos aspectos mais importantes na identidade dos povos e que as artes podem contribuir para a compreensão da diversidade e riqueza da cultura alimentar das mais longínquas partes do mundo.

Figura 4 - Cartaz da oficina. Detalhe da Obra "Vermeer"

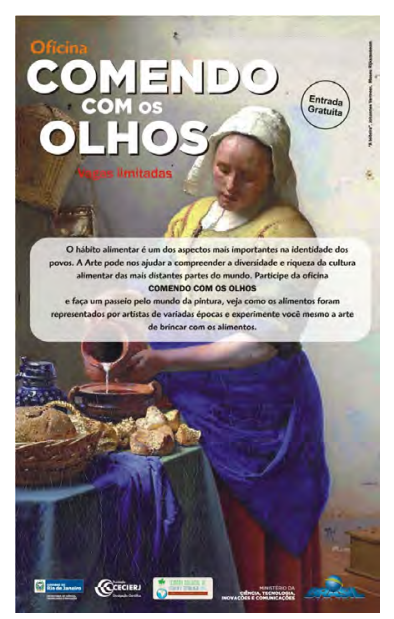

Dessa forma, propusemos aos participantes um passeio virtual pelo mundo da pintura, a partir de obras que retratassem alimentos. Um material digital foi composto por imagens de telas que exibiam alimentos pintados por artistas de variadas épocas e estilos. Após a exibição das telas e debate orientado por profissional de artes, foram associadas atividades práticas nas quais temas de biologia, química e/ou matemática foram explorados.

Nas áreas de biologia e química exploramos a extração de pigmentos de alimentos, corantes naturais e artificiais, suas propriedades nutritivas, reações químicas e a utilização desses pigmentos na elaboração de desenhos. Já no âmbito da matemática foram relacionadas noções de cálculo de peso ideal e massa corporal, por exemplo. Em síntese, buscou-se explorar a interação entre diferentes campos do conhecimento e oferecer visão 
plural e multifacetada do tema alimentação. A oficina foi realizada em três momentos principais (Quadro 1).

Quadro 1 - Descrição da oficina "Comendo com os Olhos"

\section{OFICINA COMENDO COM OS OLHOS}

PRIMEIRO MOMENTO

$O$ primeiro momento foi comum às duas modalidades de oficina: uma associada a temas da matemática e outra conjugada a conteúdos de química e biologia.
SEGUNDO

MOMENTO
Apresentação de material audiovisual contendo imagens de obras de arte que retratam alimentos. A seleção dos quadros foi realizada visando a abranger diferentes autores, épocas e estilos. Desse modo compreendemos que a discussão sobre a alimentação como fruto e expressão culturais seria facilitada. Essa etapa foi concebida e conduzida por Thelma Lopes.

No que se refere à matemática, os alunos participaram de discussão sobre noções de cálculo de peso ideal e massa corporal por meio de questões coletivas e desafios matemáticos. 0 debate gerado a partir dos números se estendeu a questões concernentes a hábitos alimentares, padrões de beleza impostos, magreza excessiva e distúrbios relacionados à alimentação, extrapolando o campo dos cálculos. Essa etapa foi concebida e desenvolvida por Wanda Medeiros Pacheco' .

Quanto aos conteúdos de química, explorou-se a confecção de corantes naturais. Tinturas foram preparadas no momento da oficina, diante do público, estimulando rica discussão que, para além das questões mais diretamente relacionadas aos conteúdos ali explorados, ampliou-se para o campo dos hábitos saudáveis de alimentação e desperdício de alimentos. Essa etapa foi concebida e desenvolvida por Célia M. da Silva Santiago e Maria da Penha Macedo Jacobina.

1 As professoras Wanda M. Pacheco, Célia M. S. Santiago e Maria da Penha M. Jacobina integraram a "Praça da Ciência Itinerante" $(\mathrm{PCl})$, programa do setor de divulgação científica do Cecierj, desde os primeiros anos do projeto e na ocasião da realização das oficinas. A coordenação da $\mathrm{PCl}$ é de Sônia Simões Camanho. 
TERCEIRO MOMENTO

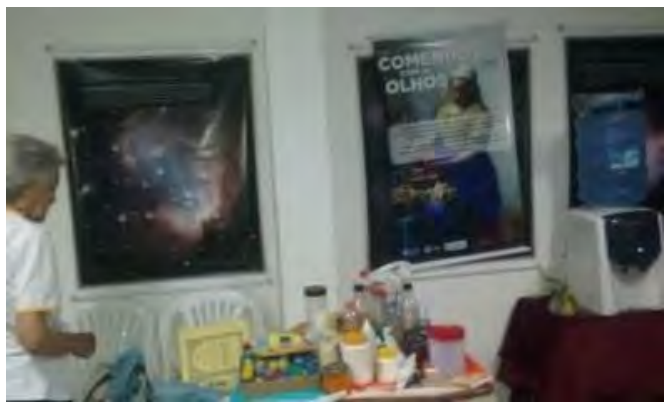

Fonte: Elaborado pelas autoras.
Roda dialógica com os participantes sobre a atividade. Como culminância dessa etapa, os estudantes foram convidados a elaborar desenhos utilizando as tinturas confeccionadas para a oficina, vivenciando, na prática, as múltiplas formas de uso dos alimentos. A etapa foi concebida e desenvolvida por Célia Maria da Silva Santiago e Maria da Penha M. Jacobina.

Figura 5 Mediadoras de Química e Biologia atuando com alunos

Fonte: Elaborada pelas autoras.

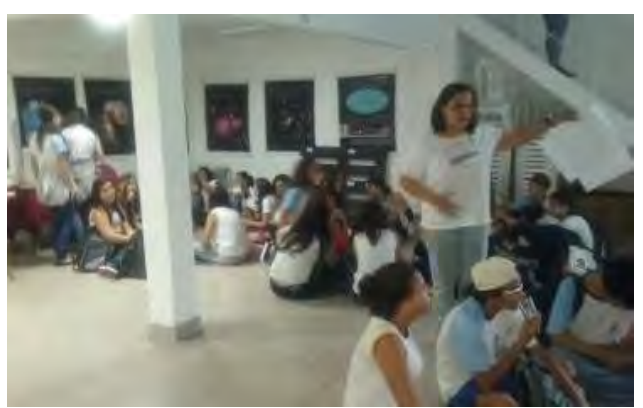

Figura 6 Desenho elaborado por aluno inspirado na obra "Verão", de Giuseppe Arcimboldo
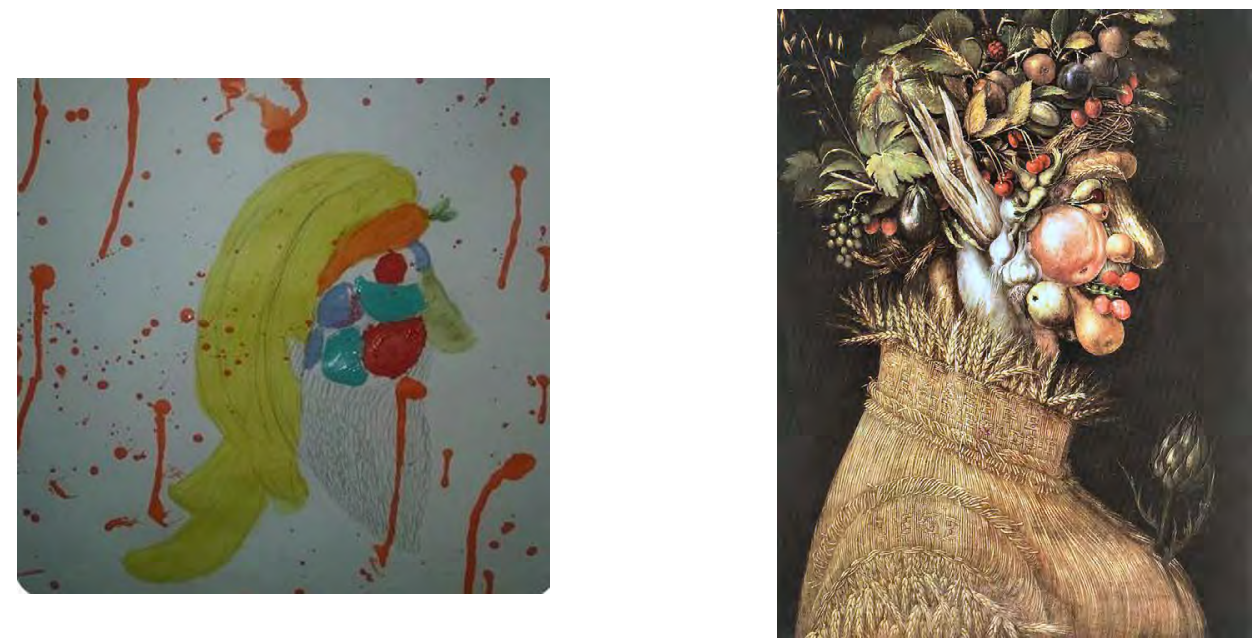

Fonte: Elaborada pelas autoras. 


\section{Considerações finais}

O desenvolvimento de estratégias educativas plurais, que envolvam diferentes áreas do saber, atores sociais distintos e diálogo com instituições de diferentes origens é condição sine qua non para assegurar a formação global do cidadão. Muito mais do que empilhar conteúdos, o protagonismo da educação deve residir em capacitar o estudante para selecionar o enorme volume de informação disponível no mundo atual. A questão crucial não é mais asseverar o acesso à informação, mas buscar dinâmicas que contribuam para a faculdade de relacionar conhecimentos. A visão dicotômica entre artes e ciências, e, por extensão, as associações equivocadas que daí podem decorrer, são acentuadas, apesar das crescentes tentativas de afastamento dos estereótipos em torno dessa visão equivocada. Têm raízes históricas e culturais. Perdemos muito quando dispensamos as artes como ponto de vista, pois deixamos de agregar significados fundamentais para compreensão dos fenômenos, sejam eles de ordem natural ou social.

Contudo, a promoção efetiva do diálogo entre os múltiplos campos do conhecimento implica longo caminho a percorrer e envolve numerosas instâncias decisórias, desde aquelas que se relacionam aos afetos e interesses individuais, passando pelas escolhas de caráter coletivo, até a atuação de instituições e implementação de políticas públicas. Não há fórmulas prontas disponíveis. Tampouco a força motriz do percurso se reduz a um suposto "temperamento renascentista", caracterizado pela imiscuição de conhecimentos, técnicas e vocações. Mais do que o desejo de aventurar-se em universo de diferentes saberes movidos por mero diletantismo, os desafios dessa jornada exigem firme disposição para compreender alfabetos e significados próprios de uma profusão de linguagens e seus respectivos pontos de vista. Em outras palavras: consiste em assumir postura na qual se constroem e reconstroem continuamente formas de interpretar, relacionar e interagir com o mundo à nossa volta.

Não se trata, portanto, de tarefa fácil, mas é possível e necessária. Hoje, mais do que nunca. Vivemos tempos controversos. Ironicamente, quando a humanidade tem a seu dispor, como nunca até então, incontáveis recursos de comunicação, proporcionados, principalmente, pelo avanço tecnológico, o diálogo tem sido cada vez mais difícil. Entrincheirados por compreensões distorcidas e polarizadas, as capacidades de refletir e ponderar têm sido embotadas e levam-nos a retroagir. Em pleno século XXI há os que passaram a defender explicitamente que a Terra é plana e a condenar o uso de vacinas ou as teorias de Darwin. Sem qualquer pudor ou argumentos razoáveis, seguem colocando em xeque o que já foi minuciosamente estudado.

Nesse cenário desolador, as iniciativas de divulgação científica assumem importante papel, uma vez que trazem em sua essência a tentativa de propiciar a familiarização das ciências junto ao público leigo, difundindo temas de forma a ampliar a cultura científica e 
o questionamento em torno das práticas que envolvem a produção de conhecimento. Em tal conjuntura, destacam-se as ações no âmbito da educação não formal, desenvolvidas, primordialmente, em centros e museus de ciência. Esses espaços têm-se mostrado complemento dialógico substancial às ações curriculares desdobradas nas escolas, uma vez que, não estando presos às certificações de aprovação do alunado ou ao cumprimento de conteúdo programático, podem fazer uso de estratégias pedagógicas mais lúdicas e criativas.

Vale destacar, ainda, como considerações finais referentes à reflexão proposta neste artigo, algumas observações: as ações de divulgação científica devem operar em diálogo com a prática escolar, de modo que, guardadas as especificidades de cada campo de atuação, complementem-se e possam propor e reinventar, conjuntamente, dinâmicas de aprendizado que contemplem as necessidades dos educandos. Ressalta-se que de nada adiantam os esforços de ambas as partes aqui mencionadas se o Estado não compreender e empreender as ações conjuntas como política pública.

Outra consideração se liga à necessidade de intensificar a apresentação de conteúdos científicos relacionados a outros saberes. Mesmo nos espaços alternativos aqui citados, não é incomum que as ciências classificadas atualmente como "humanas" sejam relegadas a segundo plano nas atividades desenvolvidas ou até ignoradas. A errônea compreensão da arte como mero instrumento a serviço da ciência também não é rara. Neste ponto, os domínios da educação refletem a sociedade como um todo, na qual se explicitam diferentes status atribuídos às artes, ciências e suas múltiplas modalidades. Ou seja, mesmo quando se intenta a educação plural e transformadora, é possível que incorramos em vícios de interpretação e perpetuemos equívocos, uma vez que a mudança cultural sempre é paulatina. É preciso, então, estar em estado de alerta e exercer a sensibilidade como forma de inteligência.

Fato é que o encadeamento de assuntos das diversas disciplinas tem sido, pouco a pouco, consolidado. A pedagogia multidisciplinar é um processo em construção que não pode ser abandonado e deve ser fortalecido por meio de diferentes aportes, dentre eles, as artes, uma vez que, ao apresentar os conteúdos relacionados entre si, estimula-se a contextualização - faculdade essencial para a compreensão das relações de causa e efeito. Se se compreende todas as imbricações históricas, e de poder, que envolviam, por exemplo, a antiga e desacertada defesa de que o Sol girava em torno da Terra, e não o contrário, facilita-se o entendimento do fenômeno astronômico em si e de que produção de conhecimento alguma é descolada de seu tempo e contexto social.

Por fim, vale sublinhar que unir arte e ciência em congraçamento, e de modo não hierarquizado, pode contribuir para o entendimento de afetos, desafetos, emoções, princípios históricos, razões sociais, interesses políticos, inclinações partidárias e tantos outros determinantes atrelados à produção do conhecimento. As experiências desenvolvidas 
nos ECs buscam constituir um ponto de partida nessa direção, pois acreditamos que tal entendimento favorece a contextualização dos fatos, que, por sua vez, é fundamental para a formação cidadã, plural, e a construção de uma sociedade na qual não se defenda o indefensável.

\section{Referências bibliográficas}

Agostinho, M., \& Casaleiro, P. (2015). Ciência e arte, SciArt: museus, laboratórios, cientistas e artistas. MIDAS, 5.

Alvarez, F. A. E. (2008). Dicionários de imagens, símbolos e mitos bachelardianos. Londrina, PR: Eduel.

Araújo-Jorge, T. C., Sawada, A., Rocha, R. C. M., Azevedo, S. M. G., Ribeiro, J. M. P., Matraca M. V. C. ... Vasconcellos-Silva, P. R. (2018). CienciArte $\odot$ no Instituto Oswaldo Cruz: 30 anos de experiências na construção de um conceito interdisciplinar. Ciência e Cultura, 70(2), 25-34.

Caires, L. (2019, 20 de fevereiro). Cientistas e cartunistas se unem para divulgar ciência em quadrinhos. Recuperado de https://jornal.usp.br/ciencias/cientistas-e-cartunistas-se-unem-paradivulgar-ciencia-em-quadrinhos/

Casa da Ciência. (2018). Portinari: Arte e Meio Ambiente. Recuperado de http://www.casadaciencia. ufrj.br/portinari/

Comitê Nacional de Organização Rio+20. (2011). Rio+20. Recuperado de http://www.rio20.gov.br/ Constituição da República Federativa do Brasil, de 5 de outubro de 1988. (1988). Brasília, DF.

De Meis, L., \& Rangel, D. (1998). A respiração e a primeira lei da termodinâmica. Rio de Janeiro, RJ: L. De Meis.

ERA Virtual. (2010). O Corpo na Arte Africana. Recuperado de http://eravirtual.org/o-corpo-naarte-africana/

Ferreira, F. R. (2010). Ciência e arte: investigações sobre identidades, diferenças e diálogos. Educação e Pesquisa, 36(1), 261-280.

Feyerabend, P. (2007). Contra o método. São Paulo, SP: Ed. Unesp.

Feyerabend, P. (2011). A ciência em uma sociedade livre. São Paulo, SP: Ed. Unesp.

Freire, P. (1983). Educação e mudança. Rio de Janeiro, RJ: Paz e Terra.

Gadotti, M. (2005). A questão da educação formal e não formal. Bramois, Suisse: Institut International des Droits de l'Enfant.

Gardair, T. L. C., Dahmouche, M. S., \& Fiães, A. (2018). Ciência e cultura: a experiência dos espaços da 
ciência vinculados à Fundação Cecierj. In Anais do 9o Seminário Internacional de Políticas Culturais (pp. 518-527). Rio de Janeiro, RJ.

Gardair, T. L. C., \& Schall, V. T. (2009). Ciências possíveis em Machado de Assis: teatro e ciência na educação científica. Ciência e Educação, 15(3), 695-710.

Gohn, M. G. (2006). Educação não formal, participação da sociedade civil e estruturas colegiadas nas escolas. Ensaio: Avaliação e Políticas Públicas em Educação, 14(50), 27-38.

Lei n. 5.692, de 11 de agosto de 1971. (1971). Fixa Diretrizes e Bases para o ensino de $1^{\circ}$ e $2^{\circ}$ graus, e dá outras providências. Brasília, DF.

Lexicon, H. (1990). Dicionário de símbolos. São Paulo, SP: Cultrix.

Lopes, T. (2005). Luz, arte, ciência... ação! História, Ciências, Saúde - Manguinhos, 12(Supl.), 401-417.

Lopes, T. (2018a, 23 de maio). Arte e ciência: ligações necessárias. Recuperado de http://

capeladaciencia.blogspot.com/2018/05/arte-e-ciencia-ligacoes-necessarias.html

Lopes, T. (2018b, 16 de dezembro). Frankenstein e a princesa da paleontologia. Recuperado de https:// www.jb.com.br/pais/artigo/2018/12/965725-frankenstein-e-a-princesa-da-paleontologia.html

Moreira, L. M., \& Marandino, M. (2015). O teatro em museus e centros de ciência no Brasil. História, Ciências, Saúde - Manguinhos, 22(Supl.), 1735-1748.

Moreira, M. A. (1999). Teorias da aprendizagem. São Paulo, SP: EPU.

Oliveira, B. J. (2006). Cinema e imaginário científico. História, Ciências, Saúde - Manguinhos, 13(Supl.), 133-150.

O Projeto Portinari. (2016). Portinari, Arte e Ciência. Recuperado de http://www.ccs.saude.gov.br/ portinari/index.php

Root-Bernstein, R., Siler, T., Brown, A., \& Snelson, K. (2011). ArtScience: integrative collaboration to create a sustainable future. Leonardo, 44(3), 192.

Serpa, F. A. (2016). A música brasileira permeada pelo universo entomológico. In Anais do 10 Colóquio de Zoologia Cultural. Rio de Janeiro, RJ.

Wagensberg, J. (2006). CosmoCaixa: the total museum through conversation between architects and museologists. Barcelona, Spain: Sacyr. 


\section{Para citar este artigo:}

Norma A - ABNT

LOPES, T.; DAHMOUCHE, M. S. Arte, educação científica e política: diálogos plurais. Conhecer: Debate entre o Público e o Privado, v. 9, n. 23, p. 141-164, 2019.

Norma B - APA

Lopes, T., \& Dahmouche, M. S. (2019). Arte, educação científica e política: diálogos plurais. Conhecer: Debate entre o Público e o Privado, 9(23), 141-164.

\section{Norma C - Vancouver}

Lopes T, Dahmouche MS. Arte, educação científica e política: diálogos plurais. Conhecer: Debate entre o Público e o Privado [Internet]. 2019 [cited Ago 1, 2019];9(23):141-164. Available from: https:// revistas.uece.br/index.php/revistaconhecer/article/view/1131 